\title{
SKLEC) Modeling Sediment Transport in the Yellow River Mouth
}

\author{
Haibo Zonga, Pingxing Dinga, Fengyan Shib \\ a.State Key Laboratory of Estuarine and Coastal Research, East China Normal University \\ b.Center for Applied Coastal Research, University of Delaware
}

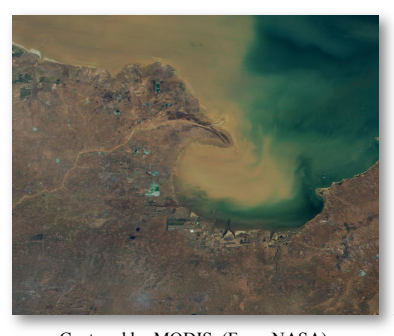

\section{Introduction}

Yellow River is famous for its high sediment concentration, which carries a huge amount of sediment into Bohai Sea during the flood season. In the mouth of Yellow River, the suspended sediment concentration (here after: SSC) are relatively high and the average depth is generally shallow. Recent studies indicated that in the shallow and micro-tide area, wave usually is a primary mechanism for bottom sediment resuspension. Most numerical studies of sediment transport in the Yellow River mouth didn't include the wave effects. To analyze the sediment transport in the Yellow River mouth with wave effect, a Coastal Sediment Transport Modeling System (CSTMS)

Captured by MODIS (From NASA) was applied in this study.

\section{Models and Method}

The CSTMS couples a third-generation wave model - SWAN, a regional ocean circulation model - ROMS and a sediment transport model. In CSTMS, wave-current interactions are presented by the short wave forcing in currents, the wave effect on bottom-boundary layer, and the current effect on waves. We used CSTMS to simulated sediment transport in the Yellow River mouth with wind wave effect and without wind wave effect, respectively.

\section{CONCLUSIONS}

We compared SSC with wave induced resuspension effects and SSC without wave induced resuspension effects in 7 stations in winter. The SSC with wave effects are $13.8 \%$ to $61.3 \%$ higher than the SSC without wave effects over 7 stations.

The geographical distribution of the differences between SSC with wave effect and SSC without wave effect was also studied. Under a real north wind condition, a region with highest values appears near the Gudong town. During the flood tide, the region is near the coastline. In the region from Shenxiangou to the old Yellow River outlet, the differences of SSC are high. During the ebb tide, the region with highest values moves out of the coastline. In the region from the old Yellow River outlet to the northeast of the Yellow River delta, the differences of SSC are high.

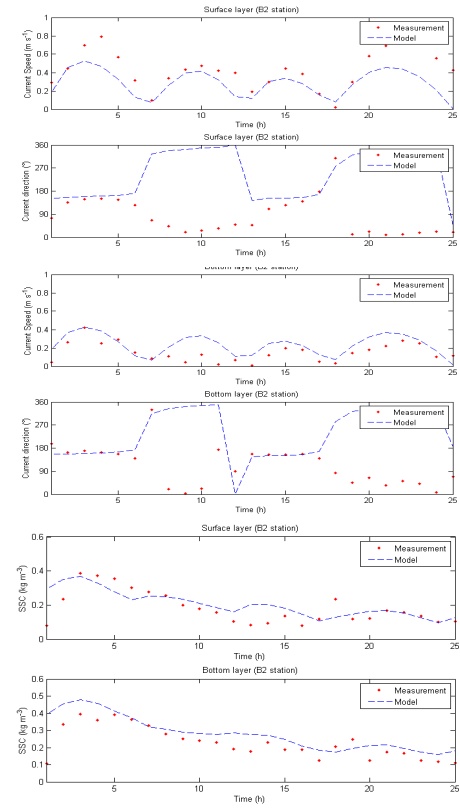

Fig.1 Model verification

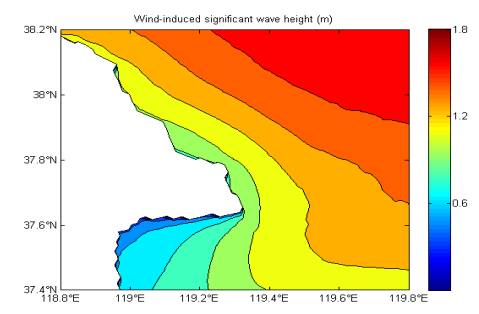

(a)

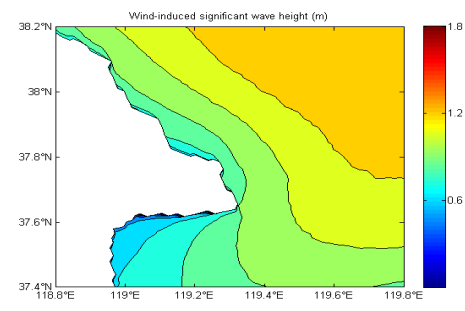

(b)

Fig.2 The geographical distribution of the significant wave height during (a) flood tide and (b) ebb tide. (Unit: $m$ )

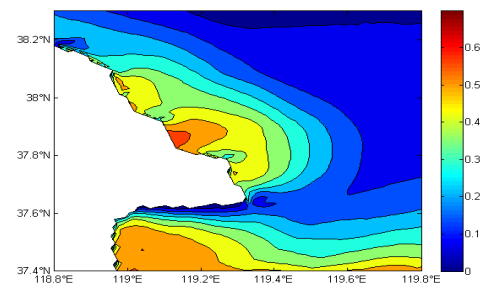

(a)

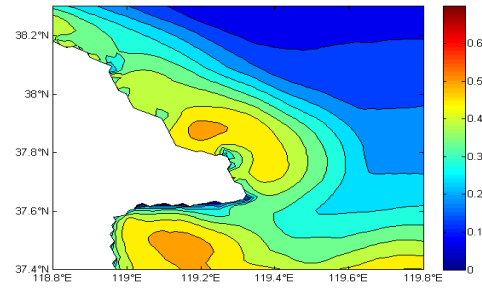

(b)

Fig. 3 The geographical distribution of the differences between SSC with wave effect and SSC without wave effect of the bottom layer during (a) flood tide and (b) ebb tide. (Unit: $\mathrm{kg} \mathrm{m}^{-3}$ )

\section{Reference}

Booth, J.G., Miller, R.L., Mckee, B.A., Leathers, R.A. (2000). Wind-induced bottom sediment resuspension in a microtidal coastal environment. Continental Shelf Research, 2, 785-806

Jiang, W.S., Pohlmann, T., Sundermann J., Feng, S.Z. (2000). A modelling study of SPM transport in the Bohai Sea. Journal of Marine Systems, 24, 175-200

Liang B.C., Li, H.J., Lee, D. (2007). Numerical study of three-dimensional suspended sediment transport in waves and currents. Ocean Engineering. 34, 1569-1583

Warner, J.C., Sherwood, C.R., Signell, R.P., Harris, C.K, Arango, H.G. (2008). Development of a three-dimensional, regional, coupled wave, current, and sediment-transport model. Computers \& Geosciences, 34, 1284-1306 